\title{
Customer-oriented Product Collaborative Customization Based on Design Iteration for Tablet Personal Computer Configuration
}

\begin{abstract}
Customers limited knowledge and technique restrains manufacturer from making them directly participate in practical product design to quickly respond to their complex and personalized demand. Based on design iteration, an approach to customer-oriented product collaborative customization is proposed for manufacturer to improve the design process. This approach uses the existing product and continuously increasing product design scheme as valuable product configuration knowledge. Meanwhile, the concept of product family is extended to design family, where the product individual and design scheme are respectively distributed into different knowledge bases. With the benefit of iterative genetic algorithm (IGA), design iteration is applied to make the existing product and design process bi-directionally evolve in the customized process to seek the optimal design, accordingly customers' operational fatigue will be lessened and their customized efficiency will be improved. Finally, the customized design of tablet PC is taken for instance to testify the maneuverability and effectiveness of the proposed approach. The experimental results demonstrate that the approach could effectively identify customers' preference and obviously improve their customization efficiency, with lessening their operational fatigue to the large extent.
\end{abstract}

Keywords: Design iteration, Collaborative customization, Interactive genetic algorithm, Customer preference

\section{Introduction}

As an effective mode to satisfy the customer demand, customization design is win-win for both customers and manufacturers (Li, Nahar, \& Fung, 2013). Many design approaches have been widely applied for different industrial design tasks(Marion, Meyer, \& Barczak, 2015), however, intelligent computing approaches, such as interactive evolutionary computation (IEC), have their own advantages, especially in the field of collaborative design for mass customization(Takagi, 2001; Liu, Zhang, \& Liu, 2011). Interactive genetic algorithm (IGA), as a subclass of IEC, facilitates non-professional customer actively to participate into design process, and then generates personalized design schemes with high customization.

In the field of industrial design, IGA can be applicable and appropriate for the design of mass-produced consumer electronics like mobile phones, which are customizable and generally have both clear visual design features and distinguishable product configuration features (Lee \& Chang, 2010; Nathan-Roberts \& Liu, 2015). Besides, IGA has been widely applied to other design or creative activities like women's dress design (Kim \& Cho, 2000), particle system graphics 
(Hastings, Guha, \& Stanley, 2009), and color blending for building (Rodriguez, Diago, \& Hagiwara, 2011). In these studies, the interactivity can be fully reflected in design process, however, the cooperation or collaboration is limited which is just as important as interactivity for design with strong customer involvement. So, collaborative product design is significant. Some co-design systems have been developed and applied into practice, in which IGA plays a very important role (Li, Lu, Fuh, \& Wong, 2005). In the evolutionary process of IGA, individual designers were allowed to share each other's design schemes via case injection to support collaboration (Quiroz, Louis, Banerjee, \& Dascalu, 2009). Clustering customer input data and grouping together similar behaviors could also be a kind of collaborative means (Kuzma, Jaksa, \& Sincak, 2009). These studies inspire us to improve design process by sharable knowledge (design schemes and existing products), which can positively influence the following design. Therefore, design iteration is considered.

Design iteration is embodied in the whole design process, and product design is not an isolated link but a dynamic evolution from products to design schemes and the schemes to new products. If individuals' design knowledge, which implies customer needs and constraints, is reasonably organized as product base and design schemes base, the potential value of existing products and acquired design schemes will be able to be recycled in following cycle of design iteration (Risdiyono \& Koomsap, 2013). The knowledge is organized in different "base", and utilized in a "family" way. Now that the concept of product family has been used to describe a series of similar products, and similarly, design family can be proposed to organize design scheme individuals. These organizational forms can be called product base and design base respectively, which are both the embodiment of knowledge accumulation reflecting different parts.

Actually, the usage of the computer-aided design approaches has led to a larger quantity of the generated design schemes, and an increase of the products that evolve from these schemes for their mass-produced mode (Hsiao, Chiu, \& Lu, 2010). When we integrate design iteration in IGA-based customization, we should consider two practical problems except user fatigue and aim at solving them. The first one is that the resources a manufacturer owns are limited. It is impossible for them to transform all the designs generated according to many different customers' preference into real products if managers bring costs into consideration, which is especially obvious to products for mass consumption, such as smartphone, tablet PC and laptop. The second one is that design schemes are continually transformed into products, accordingly the number of these products increases. It is wasteful and unnecessary to apply personalized product design if customers have found the most satisfying one from the existing product set. To deal with the challenges, we aim to find out an effective approach using IGA to utilize the increase of product and design knowledge as well as its appropriate strategies. We note that in the previous studies(Jun, Jeon, Rho, \& Lee, 2006; Mok, Wang, Xu, \& Kwok, 2012; Fung, Kwong, Siu, \& Yu, 2012), product design based on IGA is usually regarded as only a process to generate design scheme, which contains the most satisfying feature combination, from product feature space. This perspective, however, doesn't adapt to the real market environment and the practical production without considering the concept of life cycle (Smith, Smith, Jiao, \& Chu, 2012).

Customer-driven strategies and collaboration are necessary for mass customization-oriented product design, especially new product development (Shluzas \& Leifer, 2014; Peng, Heim, \& Mallick, 2014). Design iteration can be guided with the accumulation of product and design knowledge to improve collaborative product customization. Above all, this paper proposes 
customer-oriented product collaborative customization based on design iteration. To summarize, three major contributions are presented in the paper. First, the concept of product family is expanded to design family for effectively organizing and managing existing products and acquired design schemes that can be utilized in the following design process. Second, an improved approach based on design iteration, the bidirectional evolution between design schemes and products, is proposed for product customization with the benefit of IGA. Our study solves product design problems on a profounder level of product-design scheme cycle, and effectively accelerates the process to satisfy customer demand by a group decision-making strategy, which makes full use of existing product or design scheme individuals. Third, a system prototype based on the proposed approach is developed, whose 'single click' interactive mode can alleviate customers fatigue, and Tablet PC design is taken for instance to verify the effectiveness of the proposed approach, which is shown to be valuable and challenging.

The remainder of the paper is organized as follows. Section 2 reviews the related literature. In section 3, the concept of product family is extended to design family, and design iteration is integrated into IGA-based product customization. The framework is proposed to demonstrate product-design evolutionary process. Section 4 states the approach implementation according to section 3 . Section 5 applies the approach to a case study by giving a specific example for tablet PC design, and a conclusion is provided in section 6 .

\section{Literature review}

This section reviews the literature from three aspects: product customization, design iteration, and interactive genetic algorithm.

\subsection{Product customization}

As design aims at satisfying customer demand, product customization being a kind of innovative design mode, allows customers to specify their requirements, and makes manufacturers obtain advantages in price competition or raise industry profits (Bernhardt, Liu, \& Serfes, 2007). In product customization, it is customer preference identification and their satisfaction analysis that restrict improving design process (Hinckeldeyn, Dekkers, Altfeld, \& Kreutzfeldt, 2014). (Yang, Zhang, Liu, \& Xie, 2005) discussed the system integration and its structure for product customization. They proposed an evaluating rules mechanism to describe and evaluate customers' requirements. (Du, Jiao, \& Tseng, 2005) used a product quality utility analysis method to understand customer value, thereby meeting customer needs within manufacturers' capabilities. Although the methods these studies adopted could identify customers' needs and satisfy them to some extent, they have limited efficiency. To solve the issue, some researches emphasized on customer involvement in product customization. (Donnelly, Beckett-Furnell, Traeger, Okrasinski, \& Holman, 2006) discussed a product-based environmental management system that contained customer requirements driver. (Petiot \& Dagher, 2010) proposed a customer preference-oriented approach for the design of a car's headlight. (Thirumalai \& Sinha, 2011) investigated the customization of online purchase process, which had a strong customer involvement, in electronic retailing. They pointed out that both decision customization and transaction customization were dependent on customer satisfaction. Recently, some studies help improve product customization from other aspects. (Llinares \& Page, 2011) used Kano's model to evaluate customer preferences in Kansei Engineering framework. (Park, Han, Kim, Oh, \& Moon, 2013) studied the models for customer experience quantification.

(Cavusoglu, Cavusoglu, \& Raghunathan, 2007) pointed out that manufacturers only can 
profit when they output cheap products by using customization strategy. That is one of the reasons why intelligent computing approaches such as IGA, the effective methods for mass customization with relatively low cost, are becoming more and more popular in computer-aided design.

Product customization remains to be developed, from which the valuable knowledge is used to improve the following design process. For instance, it can be used to determine ergonomic and aesthetic guidelines supporting designers in decision-making (Kaljun, 2014), or solve preliminary design problem (Mazhoud, Hadj-Hamou, Bigeon, \& Remy, 2012). The knowledge could be captured by the methods in design rationale systems, product families, systems engineering, and ontology engineering (Chandrasegaran et al., 2013).

It can be seen that product customization, as a service meeting different customers' demands, is targeted at personalized preference. In order to enhance its performance, product customization should be further developed to ensure efficiency and continually improve its service quality, and thus design iteration is considered.

\subsection{Design iteration}

Design is generally an iteration process, in which, design schemes become more and more various and complex (Smith \& Tjandra, 1998). Earlier studies mainly focused on design iteration itself. (Luh, Liu, \& Moser, 1999) studied the scheduling of design projects and proposed a strategy for managing design risks with uncertain number of iterations. (Chusilp \& Jin, 2005) focused on mental iteration in conceptual design, and proved that mental iteration had both positive and negative impact on design performance. (Verstegen, Barnard, \& Pilot, 2006) explored different iteration triggers in instructional design by an empirical design process study. Now, there is a research that studies production or design process from the perspective of lifecycle. Design iteration has become a very important concept in the entire product lifecycle. (Kimura, Matoba, \& Mitsui, 2007) proposed a model in the total product lifecycle to guarantee design reliability. (Alemanni, Destefanis, \& Vezzetti, 2010) achieved product lifecycle management in computer-aided design system with model-based definition strategy. (Zheng, Bricogne, Duigou, \& Eynard, 2014) discussed data structure and data store problems in mechatronic design and explained the function of product lifecycle management systems for solving these problems. For product knowledge, (Wu, Ming, Wang, \& Wang, 2014) proposed a framework for lifecycle knowledge management. (Xu, Bernard, Perry, Xu, \& Sugimoto, 2014) proposed a method for lifecycle knowledge evaluation. (Cheung et al., 2015) focused on products' end-of-life. They studied cost problems and proposed a roadmap.

For convenience, we group the related studies, and list them in Table 1.

\section{Table 1}

Previous studies about design iteration or product lifecycle in design

\begin{tabular}{|c|c|c|c|c|c|}
\hline Article & Field & Theme & & Type & Techniques/Methods \\
\hline $\begin{array}{l}\text { (Smith \& Tjandra, } \\
\text { 1998) }\end{array}$ & $\begin{array}{l}\text { Engineering } \\
\text { design }\end{array}$ & $\begin{array}{l}\text { Design } \\
\text { iteration } \\
\text { modeling }\end{array}$ & $\begin{array}{l}\text { quality; } \\
\text { process }\end{array}$ & $\begin{array}{l}\text { Experimen } \\
\text { tal } \\
\text { observatio } \\
\mathrm{n}\end{array}$ & $\begin{array}{l}\text { Laboratory experiment and } \\
\text { comparison }\end{array}$ \\
\hline $\begin{array}{l}\text { (Luh, Liu, \& Moser, } \\
\text { 1999) }\end{array}$ & $\begin{array}{l}\text { Design project } \\
\text { management }\end{array}$ & $\begin{array}{l}\text { Design } \\
\text { scheduling }\end{array}$ & projects & $\begin{array}{l}\text { Theory } \\
\text { and }\end{array}$ & $\begin{array}{l}\text { Optimization-based } \\
\text { methodology }\end{array}$ \\
\hline
\end{tabular}




\begin{tabular}{|c|c|c|c|c|}
\hline & & & $\begin{array}{l}\text { applicatio } \\
\mathrm{n}\end{array}$ & \\
\hline (Chusilp \& Jin, 2005) & $\begin{array}{l}\text { Conceptual } \\
\text { design }\end{array}$ & $\begin{array}{l}\text { Mental iteration; } \\
\text { design performance }\end{array}$ & $\begin{array}{l}\text { Theory } \\
\text { and } \\
\text { applicatio } \\
\mathrm{n}\end{array}$ & Correlation analysis \\
\hline $\begin{array}{l}\text { (Verstegen, Barnard, } \\
\text { \& Pilot, 2006) }\end{array}$ & $\begin{array}{l}\text { Instructional } \\
\text { design }\end{array}$ & $\begin{array}{l}\text { Causes for iteration; } \\
\text { Iterative design } \\
\text { process }\end{array}$ & $\begin{array}{l}\text { Empirical } \\
\text { study }\end{array}$ & $\begin{array}{l}\text { Instructional System Design } \\
\text { (ISD) model }\end{array}$ \\
\hline $\begin{array}{l}\text { (Kimura, Matoba, \& } \\
\text { Mitsui, 2007) }\end{array}$ & $\begin{array}{l}\text { Designing } \\
\text { product } \\
\text { reliability }\end{array}$ & $\begin{array}{l}\text { Product quality and } \\
\text { functionality; product } \\
\text { modeling }\end{array}$ & $\begin{array}{l}\text { Theory } \\
\text { and } \\
\text { applicatio } \\
\mathrm{n}\end{array}$ & Reliability design method \\
\hline $\begin{array}{l}\text { (Alemanni, } \\
\text { Destefanis, \& } \\
\text { Vezzetti, 2010) }\end{array}$ & $\begin{array}{l}\text { Product lifecycle } \\
\text { management }\end{array}$ & $\begin{array}{l}\text { Computer-aided } \\
\text { design model }\end{array}$ & $\begin{array}{l}\text { Theory } \\
\text { and } \\
\text { applicatio } \\
\mathrm{n}\end{array}$ & $\begin{array}{l}\text { Model-based definition } \\
(\mathrm{MBD})\end{array}$ \\
\hline $\begin{array}{l}\text { (Wu, Ming, Wang, \& } \\
\text { Wang, 2014) }\end{array}$ & Product lifecycle & $\begin{array}{l}\text { Knowledge } \\
\text { management; } \\
\text { collaboration; } \\
\text { Information } \\
\text { technology }\end{array}$ & $\begin{array}{l}\text { Theory } \\
\text { and } \\
\text { applicatio } \\
\text { n }\end{array}$ & PLKM framework \\
\hline $\begin{array}{l}\text { (Xu, Bernard, Perry, } \\
\text { Xu, \& Sugimoto, } \\
2014)\end{array}$ & $\begin{array}{l}\text { Product lifecycle } \\
\text { design }\end{array}$ & $\begin{array}{l}\text { Knowledge } \\
\text { management; } \\
\text { knowledge } \\
\text { evaluation }\end{array}$ & $\begin{array}{l}\text { Theory } \\
\text { and } \\
\text { applicatio } \\
\mathrm{n}\end{array}$ & $\begin{array}{l}\text { Knowledge quantification } \\
\text { approach }\end{array}$ \\
\hline $\begin{array}{l}\text { (Zheng, Bricogne, } \\
\text { Duigou, \& Eynard, } \\
\text { 2014) }\end{array}$ & $\begin{array}{l}\text { Mechatronic } \\
\text { engineering }\end{array}$ & $\begin{array}{l}\text { Design methods; } \\
\text { product models }\end{array}$ & Survey & Criteria assessment \\
\hline (Cheung et al., 2015) & Concept design & $\begin{array}{l}\text { Disposal costs; } \\
\text { product end-of-life }\end{array}$ & $\begin{array}{l}\text { Theory } \\
\text { and } \\
\text { applicatio } \\
\mathrm{n}\end{array}$ & $\begin{array}{l}\text { Generic cost estimating } \\
\text { approach }\end{array}$ \\
\hline
\end{tabular}

Although some of the previous researches study product lifecycle or design iteration from different perspectives or different phases in lifecycle, few of them focus on the important guidance role played by iteration itself in concrete following design process. In order to integrate the concept of design iteration into product customization, IGA, as an effective method, is applied.

\subsection{Interactive genetic algorithm (IGA)}

The genetic algorithm (GA) originates from natural selection process and population genetics theory, and has been widely used as a kind of stochastic search algorithm. In GA, chromosome individual represents a solution to a problem, and the solution is improved by a series of genetic operators as a population evolves. As it is capable of effectively solving complex 
optimization problems in any field, the algorithm has been applied in design fields, such as industrial product design and art design, and the like (Renner \& Ekárt, 2003). (Poirson, Dépincé, \& Petiot, 2007) used GA to solve the user-centered design problem, and presented an application of trumpet design. After improving GA, (Fung, Kwong, Chan, \& Jiang, 2014) proposed a guided search method to determine the optimal design attribute settings. (Lorenzini et al., 2014) presented a constructed design task of Y-shaped cavities, and used GA to search for the best geometry.

Product design is featured by implicit performance indexes (Dou \& Zong, 2014). For design tasks, it is difficult to define fitness functions because it is not easy to judge a design scheme to be good or not, which is the limitation of GA in design field. Therefore, interactive genetic algorithm (IGA) was proposed to solve the problem for its interactive mechanism. During the IGA-based process, customers directly evaluate individuals in population and judge their preference judgment respectively. In other words, individual fitness is decided by customer preference rather than a calculating function. In the initial stage of its use for design, IGA was used primarily in the creative design field and its computer-aided design system. For example, (Cho, 2002) developed human-oriented evolutionary systems based on IGA, and applied them to fashion design. Recently, many researchers start to study on IGA applied into different design tasks. (Babbar-Sebens \& Minsker, 2012) used IGA to solve groundwater monitoring design problems. (Mok et al., 2013) developed a design support system for sketch design under an IGA model. (Yannou, Cluzel, \& Dihlmann, 2013) proposed a model based on IGA by a Fourier analysis approach for car profile design. At the same time, some novel concepts or IGA approaches were also proposed, such as the IGA approach proposed by (Gong, Yao, \& Yuan, 2009), in which individual fitness was calculated according to customers sensitiveness instead of being directly assigned by customers. (Bush \& Sayama, 2011) proposed a novel iterative model called hyper-interactive evolutionary computation (HIEC), which made customers more positively and actively participate in the interactive process.

It is noted that IGA is much improved and widely applied to different design tasks. If it is applied into product customization on the basis of design iteration, the valuable knowledge extracted design iteration product customization will be achieved, and the customers' fatigue will be much relieved as the valuable knowledge could be effectively organized and used to guide the following product customization.

\section{Product-design iteration}

Design scheme is the conception of one product's features, sense of beauty and functions. After the productization of a design scheme, a product is shaped. Product family is a series of product individuals that have similar feature classification but different configuration. In our approach, product individuals are organized as a base called product base, similarly, the design scheme individuals in design family are organized as design base. Despite product and design scheme can be represented as one individual, product base and design base represent different sets respectively. They embody the organization and management of existing products, as well as, the obtained design, which can be regarded as market and customer knowledge for design (Jin \& Peng, 2009). For convenience, the paper mainly focuses on product base and design base below because they are easier for common customers to understand.

Design quality and the customer satisfaction for the obtained design scheme are much improved by effectively using knowledge. Being the accumulation of the existing product 
knowledge, product base includes the most customers' preference, and it could accelerate customers to find their satisfying individual. Design base collects customized design schemes embodying individual preference knowledge and influences the following design process in the details.

A 4-step product-design evolutionary process is shown in Fig. 1.

A cycle of design iteration includes 4 steps, but any one of them can be the starting point of the current cycle. These 4 steps are presented below:

Step 1. Design schemes originate from the last cycle of design iteration. Different design schemes generated by different customers using IGA will all be added into the design base.

Step 2. Because of the restriction of resource and costs restriction, manufacturers generally adopt some strategies to transform the best design into real product. In order to improve design iteration effectiveness, for manufacturers, a reasonable strategy is to select the individual from design base that has the most significant difference compared with all products in original product set, which ensures the diversity of product base.

Step 3. Design scheme, which is selected to realize production, will be added into product base as a new individual.

Step 4. In this step, with customer's participation, a new design is generated on the basis of the product base, which demonstrates the workflow of IGA. Customer first judge whether he can find a satisfying individual from product base or not, otherwise, product design will start. The products in product base are used to generate initial population by particular rules. In order to speed up the IGA process, design scheme in design base will be added into current population by a customer preference recognition strategy.

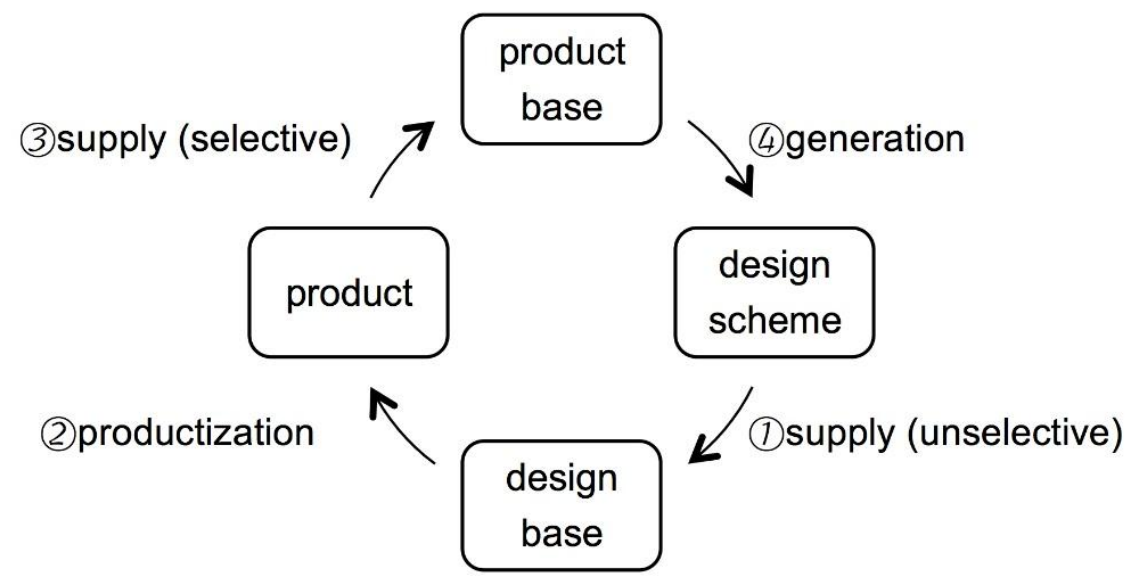

Fig. 1. 4-step product-design evolutionary process.

In the model, with the proceeding of design iteration, both the amount of product information and design scheme information will increase, which are not only used to generate the best scheme for one design task but also used to improve the following design process. Customer collaboration in the process manifested customer design is improved by design schemes reflecting the customized preference of the others.

For the convenience of implementation, the approach is summarized in the form of algorithms. The details are described as follows:

Algorithm 1: obtain customers' most satisfying individuals 
Input: the current set of products (product base)

the current set of design schemes (design base)

a set of customers

Output: customers' most satisfying individuals

1: for each customer do

2: if productization is needed, then

3: $\quad$ determine the best design scheme according to manufacturer's strategies

4: $\quad$ transform the best design scheme into real product

5: $\quad$ refresh the product base

6: $\quad$ end if

7: if find the most satisfying individual in the current product base, then

8: $\quad$ record this individual as the current customer's most satisfying one

9: else

10: create initial population according to the current product base

11: repeat //a IGA-based design process to obtain design scheme

12: $\quad$ select one relatively satisfying individual from the population

13: if customer think it is the most satisfying one, then

14: record this individual as the current customer's most satisfying one

15:

16: break

else

17: $\quad$ refresh the population according to customer selection by IGA

//design base knowledge is utilized

18: $\quad$ end if

19: $\quad$ until customer gives up the design process

20: end if

21: refresh the design base

22: end for

23: return customers' most satisfying individuals

\section{Collaborative customization integrating design iteration by IGA}

Section 3 integrates design iteration into interactive genetic algorithm-based collaborative customization. In section 4, the approach implementation will be specified.

\subsection{Customization process}

Product base $P$ is defined as a set of products, design base $D$ as a set of design schemes. $p_{i} \in P(i=1,2 \cdots n)$ represents an individual $p_{i}$ as a product in product base, of which $n$ is the quantity of products in the current product base. Similarly, $d_{t} \in P(t=1,2 \cdots m)$ represents an individual $d_{t}$ as a design scheme in design base, of which $m$ is the quantity of design schemes in current design base. For the design iteration of one product, $p_{i}$, as well as $d_{t}$ represents a $q$-dimensional vector whose form is $\left(v\left(f_{1}\right), v\left(f_{2}\right), \cdots v\left(f_{q}\right)\right)$, of which $q$ is the quantity of product features, which are classified by design demand. $v\left(f_{q}\right)$ is the $q^{\text {th }}$ characteristic value $f_{q}$ of any product $p_{i}$ or design scheme $d_{t}$.

Step 1 is from design schemes to design base. It is supposed that there have been multiple design schemes generated by different customers during IGA design process, and then these schemes should be added into their original design base. For a single operation, the design 
scheme of the $i^{\text {th }}$ customer's best individual in the $j^{\text {th }}$ generation is treated as the final outcome of design result, and added into design base $D^{\prime}$. The new design base is $D$ :

$$
D=D^{\prime} \cup\left\{\left(v\left(f_{1}\right), v\left(f_{2}\right), \cdots v\left(f_{q}\right)\right)_{i}^{j}\right\}, j=0,1,2 \cdots, i=1,2 \cdots
$$

This operation will not be launched if customer directly has found his most satisfying individual from product without the IGA design process.

Step 2 is from design base to products. According to preceding text, manufacturers can't transform all workable schemes into products (for mass production). Therefore they adopt some strategies, and select the best design for productization. These strategies can be design principles, production capacity or anything that may become the factor to limit the evolutionary from designs to real products. In order to continually improve the following design iteration, an available strategy should ensure the product diversity and provide customers with a larger selection range, so the design scheme farthest from the product base is selected, and then added into product base as a new product.

With an ideal point method, Euclidean distance is calculated as evaluation function, then

$$
U\left(d_{t}\right)=\frac{1}{n} \sum_{i=1}^{n}\left[\sum_{j=1}^{q}\left(v_{p_{i}}\left(f_{j}\right)-v_{d_{t}}\left(f_{j}\right)\right)^{2}\right]^{\frac{1}{2}} \quad(t=1,2 \cdots m)
$$

Of which $n$ is the quantity of products in current product base, $m$ the quantity of design schemes in current design base, and $q$ the number of product features. Every design scheme can be calculated an average distance between itself and each individual in product base by this evaluation function.

Step 3 is from products to product base. This step is similar to the transformation from design schemes to product base. The best design is selected and changed into a product. The $d_{t}$ corresponding with $\max _{d_{t} \in D} U\left(d_{t}\right)$ is the one need to be added into product base:

$$
P=P^{\prime} \cup\left\{d_{t} \mid U\left(d_{t}\right)=\max _{\forall d \in D} U(d), t=1,2 \cdots m\right\}
$$

Step 4 is from product base to new design scheme. This step in which customers directly join is the key stage to generate new designs. The process is summarized in Fig 2. IGA is mainly used in the step, and its flowchart is stated in section 4.2. 


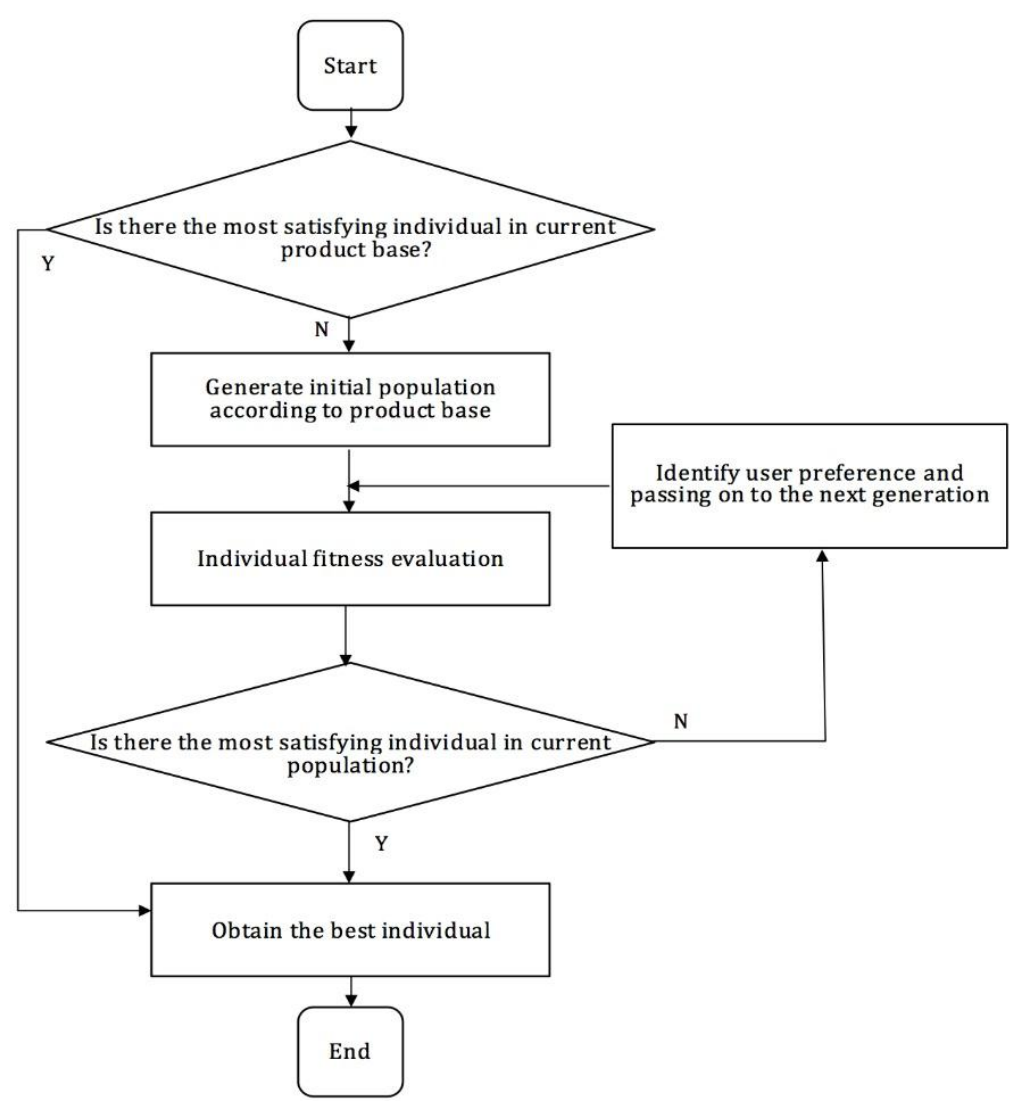

Fig. 2. New design individual generation from product base using IGA.

\subsection{Interactive genetic algorithm process}

\subsubsection{Initial population generation}

With a classified catalogue of all products, a graphical user interface (GUI) is used to judge whether there is the most satisfying individual in product base or not. The product design starts if customer thinks that there is no satisfying individual, and an initial population that contains $\mathrm{N}$ individuals is generated according to products in product base. A larger $N$ will lead to serious customer fatigue, and a smaller $N$ may lead to the problem of over speed convergence. Generally, $N=4 \sim 9$ is reasonable and acceptable (Rodriguez, Diago, \& Hagiwara, 2011; Mok et al., 2013).

It is of the most efficiency to add the latest product into product base by the last cycle of design cycle of design iteration, with the best reference value for the next design. This product is preferentially put in the initial population. The rest of $N$ - 1 individuals are randomly selected from product base.

After all the products has been added into the population from product base, if the quantity of individuals is still less than $N$ in initial population, an individual of a random feature combination will be created and added into the population. The process will repeat and won't stop until the number of individuals in population reaches $N$.

\subsubsection{Structure of the individuals}

The individuals of product and design scheme are represented by the same code scheme. For each characteristic value $f_{q}$, it can get value from a discrete value range. Those whose value range is continuous can also be classified into several different discrete styles. The site on chromosome matches individual features, and they are sorted in the order of the individual features in vector. For feature $f_{q}$, it has several possible values, which are coded and sorted one 
by one by the significance level of characteristic difference from one extreme to another extreme by taking design principles as the guidance. For instance, feature color contains 4 different values, which can be sorted from the coolest color to the warmest color, and coded as $0,1,2,3$. One part of a product has 3 styles, which can be sorted from the most conservative one to the most exaggerated one, and coded as 0,1,2. Here the design principles mainly depend on existing design paradigm and the experience of professional designers. The reason why we code individuals like this is that this coding method is more convenient to calculate individuals' evaluation function value in step 2 .

\subsubsection{Genetic operations}

The genetic operations include selection, crossover, and mutation. For crossover, customer selects the best individual $X$ from the current population through GUI. Every characteristic value of the individual is counted for customer preference identification. With population evolution, customer builds up more and more clear cognition of evaluated object, and manifesting as their preferences to some features. We define $C_{v_{n}\left(f_{j}\right)}$ as a counting value of the $n^{\text {th }}$ possible value of feature $f_{j}$, and it increases with customer's selection. In the $t^{\text {th }}$ population, the feature value $v\left(f_{j}\right)$ associated with $\max C_{v_{n}\left(f_{j}\right)}$ composes vector $Y$ :

$$
\begin{gathered}
v_{\max }\left(f_{j}\right) \in\left\{v_{i}\left(f_{j}\right) \mid C_{v_{i}\left(f_{j}\right)} \underset{\forall i \leq n, i \in N^{+}}{\left.=\max _{v_{i}\left(f_{j}\right)}\right\}}\right. \\
Y=\left(v_{\max }\left(f_{1}\right), v_{\max }\left(f_{2}\right), \cdots v_{\max }\left(f_{j}\right), \cdots v_{\max }\left(f_{q}\right)\right)
\end{gathered}
$$

It's just the customer preference when the population evolved into the $t^{\text {th }}$ generation. $Y$ is compared with every design scheme in design base respectively to find the closest individual who has the most number of the same features as $Y$. The individual will be substituted into the next generation at a certain probability, which is calculated by confidence coefficient function $R(t)$ (Gong, Zhou, \& Li, 2005), when it fulfills the threshold value condition (the number of the same features as $Y$ isn't less than a set value $\varepsilon$ ). This operation happens after mutation operation, and the individual to be replaced is randomly selected from the population. Confidence index $\alpha$ and parameter $T_{s}$ are given depending on the demand. The function $R(t)$ reflects the process that customer gradually understands the evaluated object.

$$
R(t)=\left\{\begin{array}{cc}
1+e^{-\alpha \cdot T_{s}}-e^{-\alpha \cdot t}, & t<T_{s} \\
1 & , t \geq T_{s}
\end{array}\right.
$$

Multi-point discrete crossover operator is applied at a probability $p_{c}$. When applying crossover, for each individual in current population that hasn't yet been selected, an unordered binary string is randomly generated whose length is same as that of an individual chromosome. The ratio of 0 and $1 r$ is decided by the given parameter. Every " 1 " position of each chromosome is the place where the feature value will be replaced by the mapping value of individual $X$ selected by customer.

When the crossover is completed, mutation operation starts at a probability $p_{m}$. Normally, $p_{m}$ equals to $0.05-0.15$. The gene of selected individual that need mutation randomly changes its feature value once within the available value range. Population capacity is $N$, and the number of one individual's gene points is $q$, the same as feature quantity. $N * q$ random numbers between 0 and 1 are generated after individuals undergo mutation once. For each number,

$$
k=\text { random }(0,1)
$$

All the genes of individuals in the population are sorted in a single sequence, and then the $k \leq p_{m}$ positions just are the place where individual's features mutate. 


\subsubsection{Terminal criterion}

The process will stop when the customer generates the most satisfying individual. As the best design scheme, this individual will be added into design base, and then every step will be repeated again in the next cycle of design iteration. Design schemes in design base may come from different customers' design results in same iteration period, or may be the design results of one customer in different iteration period.

\section{A case study}

Tablet PC is a kind of product for mass consumption, which is strict in the quality of industrial design. Tablet PC design is used as an example to explain the details of the proposed approach because the product of this type, as a kind of electronic product, has been upgraded at a high rate with obvious and frequent product-design iteration. Besides, tablet PC is customizable mass produced product. Visual design features (color, size, etc.) and product configuration features (Internal storage, hard disk storage, etc.) are all available for customized design contents. Although we take tablet PC for instance here, according to the same implementation process, the approach can easily generate some other similar mass-produced products whose components are usually organized in a modular way. These products generally have both clear visual design features and distinguishable product configuration features.

Despite tablet PC is the only product we study in the research, the combination of different characteristic values produces a series of concrete design schemes. Tablet PCs' characteristic values are identified and classified in accordance with the reference of some famous E-business websites' standards, as well as, the design experience. They are shown in Table 2. Possible values of each feature are coded as integers beginning with 0 , and sorted by the significance level of characteristic difference from one extreme to another extreme. Some functional features, such as Wi-Fi and Bluetooth, will finally become tablet PCs' common features, therefore they are not taken into consideration. Even so, our characteristic value classification covers most typical dimensions for product design including usability (e.g. operating system), affection (e.g. material), and user value (e.g. price) from two feature aspects: visual design and product configuration. Fig. 3 is a 3D rendered graph of one tablet PC design scheme. It presents all visual design features of the tablet PC in normal style though product configuration features can't be reflected in a visual method.

\section{Table 2}

Listing of the characteristic values and their codes

\begin{tabular}{cllll}
\hline Name & \multicolumn{3}{l}{ Values and codes } & \\
\hline Color $f_{1}$ & Black & Gray & White & $\begin{array}{l}\text { Multi- } \\
\text { color }\end{array}$ \\
& 0 & 1 & 2 & 3 \\
\hline Material $f_{2}$ & Carbon & Plastic & Metal & \\
& fiber & & & \\
& 0 & 1 & 2 & \\
\hline Style $f_{3}$ & For & Normal & Transformable \\
& children & & & \\
& 0 & 1 & 2 & \\
\hline
\end{tabular}




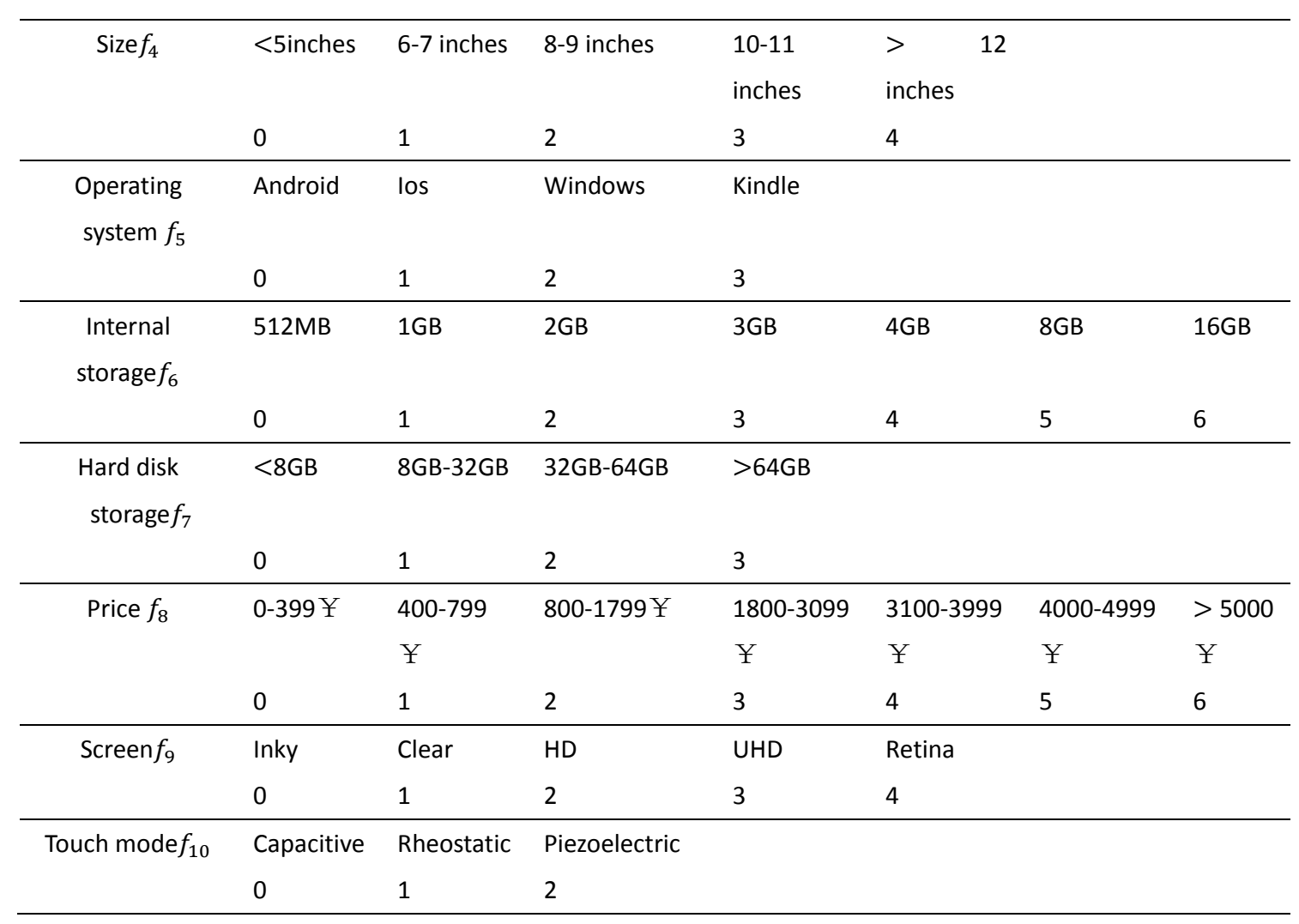

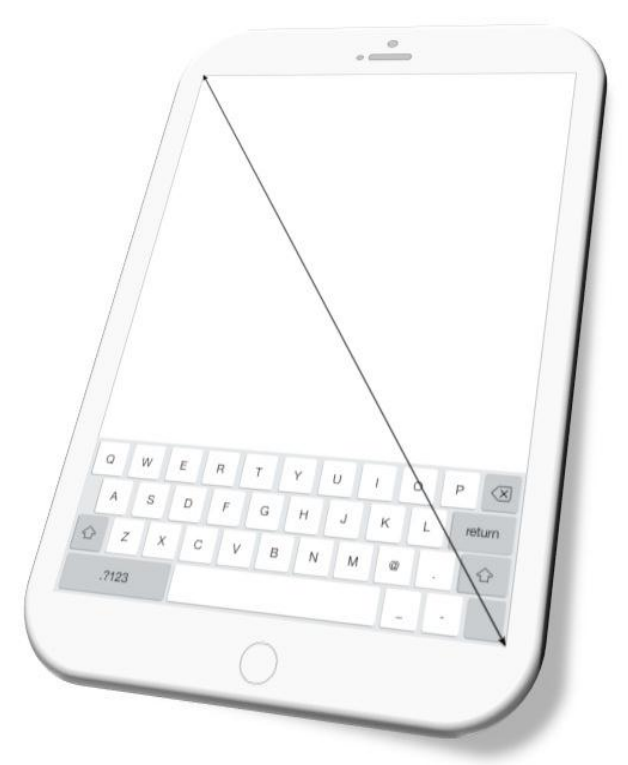

Fig. 3. A $3 D$ rendered tablet $P C$ design scheme.

Any product $p_{i}$ or design scheme $d_{t}$ can be represented as a vector $\left(v\left(f_{1}\right), v\left(f_{2}\right), \cdots v\left(f_{10}\right)\right)$, which is written in simplified form, a character string " $v\left(f_{1}\right) v\left(f_{2}\right) \cdots v\left(f_{10}\right)$ ". $q=10$ is the number of features. As the experiment participants are all Chinese, monetary unit RMB is chosen to mark the price. Sometimes, the relationship among product features is mutually affected and restricted, so it is not considered in this case, the same with signaling theory, as well as, the influence of system interface itself on user perceptions either (Wells, Valacich, \& Hess, 2011).

Now, one cycle of design iteration is stated here. A web based design system developed by 
HTML, CSS and JavaScript is shown in Fig.4. To simplify the problem, the initial stages of product base and design base are given randomly and some necessary parameters are configured in advance, shown in Table 3. In this case, initially, the number of products in product base is $1(n=1)$, the number of design schemes in design base is $3(m=3)$. The parameter $T_{s}=3$ is reasonable because product base can help users create their preference awareness to some extent before IGA-based design process starts.

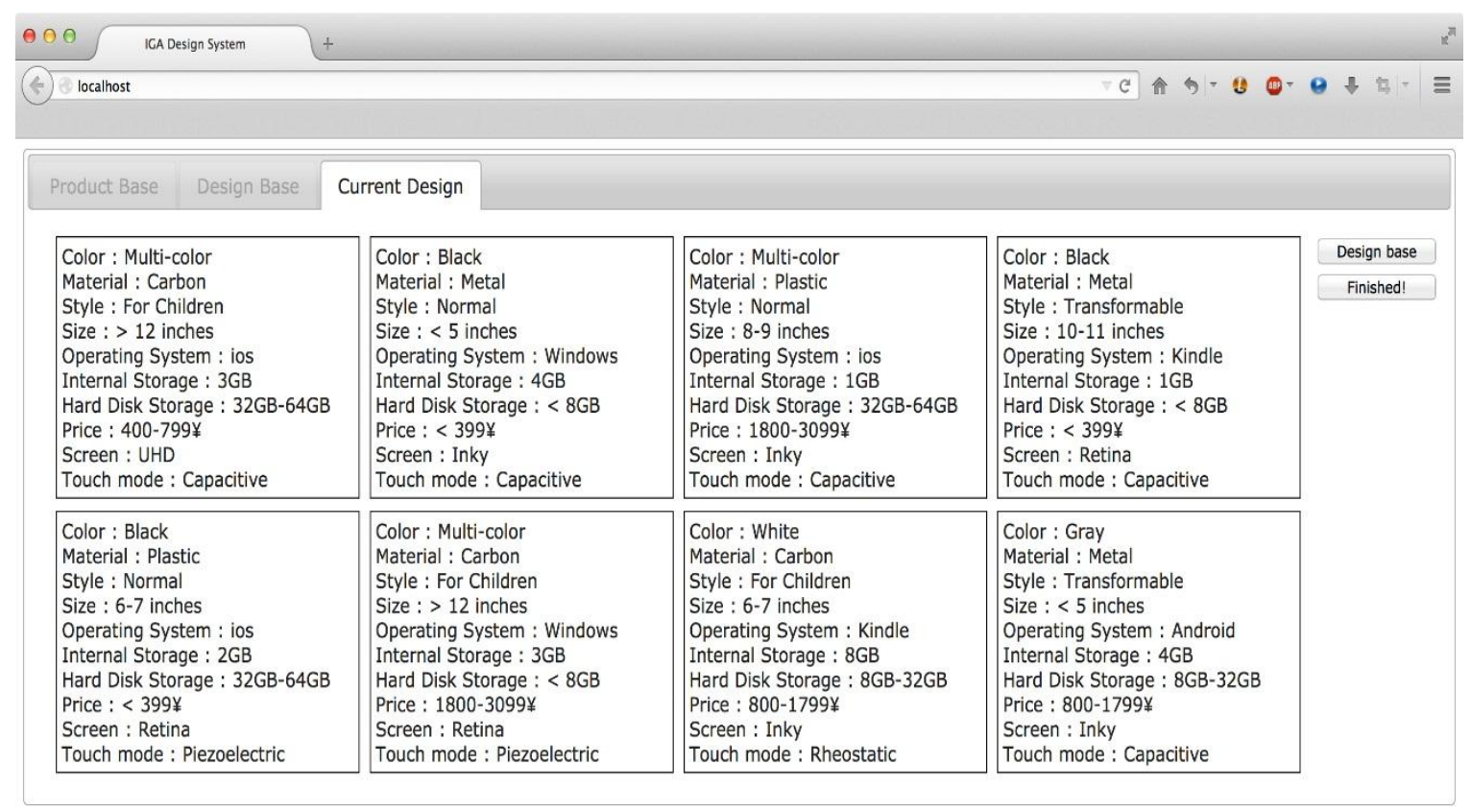

Fig. 4. Design system screenshot with a population of 8 individuals in one IGA-based design process.

48 volunteers are randomly selected as subjects to take part in the study, and therefore 48 results are collected in the experiment. All of users have basic understanding of tablet PC, and once have tablet PC consumption or operation experience. So, they can represent the majority of tablet PC customers' user experience. As shown in Fig. 5, in the system, even if some users can't fully understand the technical terms describing tablet $P C$ features, such as GB and hard disk, the difficult features are shown in simple language to make themselves understandable. For each user, the first thing is to browse through product base and judge whether there is the most satisfying individual or not. If not, the 8 individuals are presented on the screen, which is repeated after the most satisfying individual is found out. Users are allowed to judge when to stop their design process. When the user has experienced several genetic operations, he may receive the most satisfying design. It is added into design base, and after several genetic operations, the most satisfying design can be figured out, and added into design base. The next cycle of design iteration starts by repeating the previous steps.

\section{Table 3}

Listing of system parameters

\begin{tabular}{ll}
\hline Parameter(s) & Value(s) \\
\hline The initial states of product base & $\left\{p_{1}=0111122042\right\}$ \\
The initial states of design base & $\left\{d_{1}=0210240000, d_{2}=0223310040, d_{3}=0123100001\right\}$
\end{tabular}




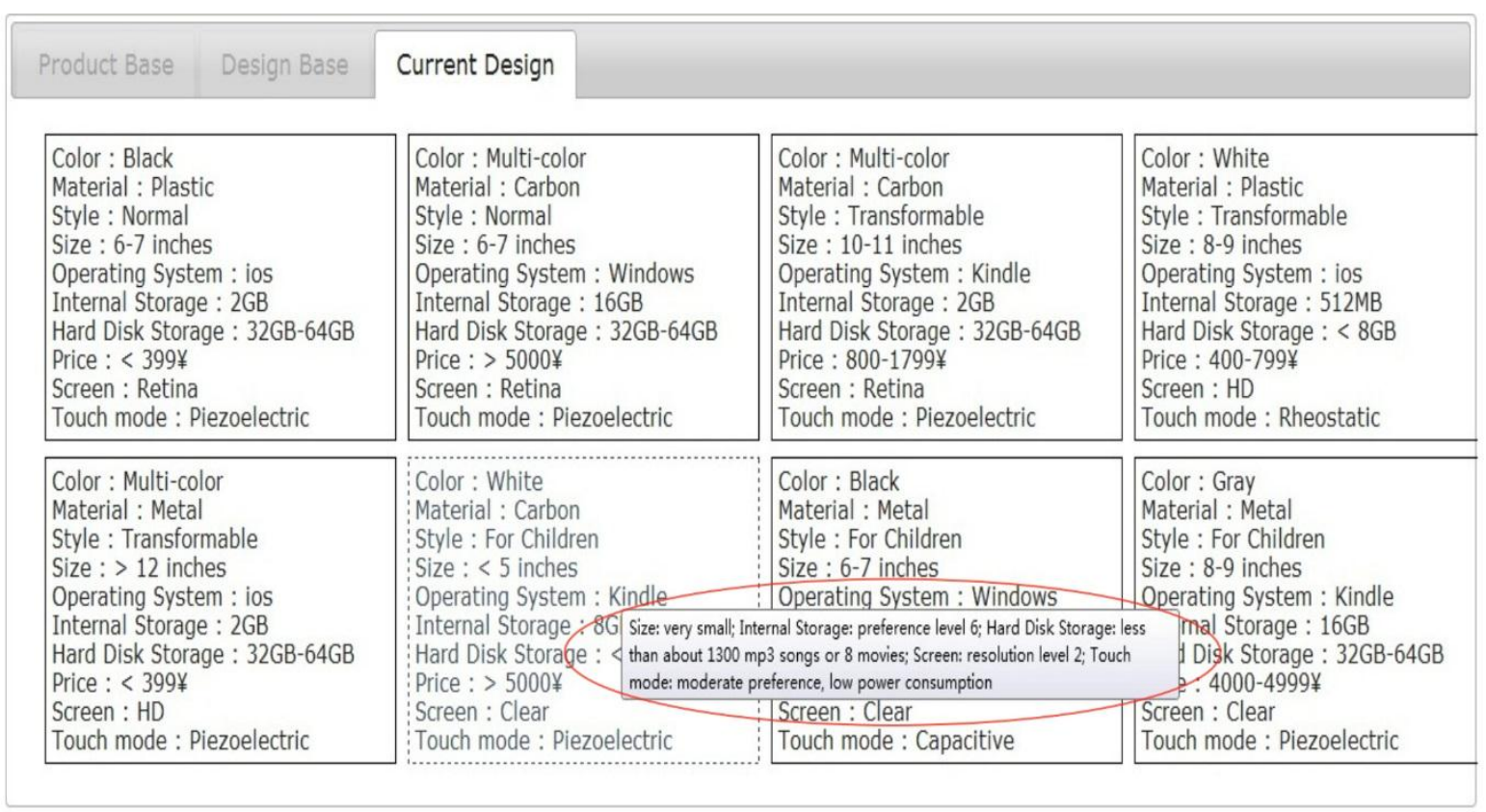

Fig. 5. Design system real-time screenshot with a feature tip.

In one IGA-based product design process, only one user is involved, however, different users can jointly maintain one product base and one design scheme base by conducting their respective IGA product design steps. It is assumed that productization occurs after every 5 users finished their experiment process

After a user finished the operation, two questions about the operating experience and final result satisfaction is presented. Both these two questions included five-point scales:

Q1: What do you think of your previous operating experience?

1. Very bad 2. Bad 3. Medium 4. Good 5. Very good

Q2: How satisfied are you with the final result?

1. Very bad 2. Bad 3. Medium 4. Good 5. Very good

To explain in details, the first user's concrete operation is highlighted here. In the system, the initial state of product base is $P=\left\{p_{1}=0111122042\right\}$, the initial state of design base is $D=\left\{d_{1}\right.$ $\left.=0210240000, d_{2}=0223310040, d_{3}=0123100001\right\}, n=1, m=3$. In product base is only one product which doesn't satisfy the user. Therefore, IGA-based product design starts.

The evolution of the first generation is shown in Table 4. There are no products transformed from the last design result as individuals to be added in the initial population. Because $n<N$, additional 7 individuals need to be generated randomly after adding $p_{1}$ from product base to the population. 
Table 4

The evolution of the first generation

\begin{tabular}{cccc}
\hline No. & Initial population & $\begin{array}{c}\text { Population after } \\
\text { crossover }\end{array}$ & Population after mutation \\
\hline 1 & 0111122042 & 2111122020 & 1111122020 \\
2 & 1011321242 & 2111321222 & 2111301222 \\
3 & 0111122440 & 2111122440 & 2111122440 \\
4 & 0014231310 & 2111262010 & 2111263330 \\
5 & 2111162020 & 2111162020 & 2111162020 \\
6 & 0204160132 & 2201162132 & 2201152132 \\
7 & 0214060132 & 0211060122 & 0211060122 \\
8 & 0214140010 & 0214140020 & 0214140020 \\
\hline
\end{tabular}

The user selects the individual 2111162020 as the current satisfying one according to his preferences. The " 01 " control strings for crossover are generated randomly, and the quantitative proportion 0 to 1 is set up as 1 in this case. The control strings decides the points of genes to conduct crossover.

Because the user has only conducted selection operation one time, the current user preference maintains 2111162020 . Compared with it, the feature coincidence number of every design scheme is less than $\varepsilon$, so the user preference will not be replaced into population, otherwise an individual selected randomly from the current population will be replaced by the design scheme in design base that is the nearest to the current user preference at the probability $R(1)=0.0578$. After that, the $2^{\text {nd }}$ generation is reached, and the user begins to conduct new selection operation. This process won't stop until the most satisfying individual is found by a user, or it will stop at the user' willingness. After that, the design result is added into design base as a new design scheme, and then the next cycle of design iteration starts and so on.

The increment of the number of individuals in product base and design base is shown in Fig. 6 . As the design iteration goes on, more and more individuals generated by users' operation are added to product base and design base. The following design process will be improved by users' increasing information, which facilitates to find out the most satisfying individual. It is observed that two trend lines are all non-linear but have a linear progression trend.

For product base, the number of individuals in product base depends on productization strategies. In real market, manufacturer decides the strategies. In this case, our own strategy is reflected as a concrete iteration parameter. That's why the quantity of products in product base changed regularly with product-design evolution. Theoretically, it is possible that the quantity changes irregularly. If there has been an individual in product base just as same as the design scheme selected to become product, the quantity will not change after productization in the present iteration.

For design base, if one user has found the most satisfying individual directly from product base without IGA design process, the new design scheme to be added into design base will not be created. 


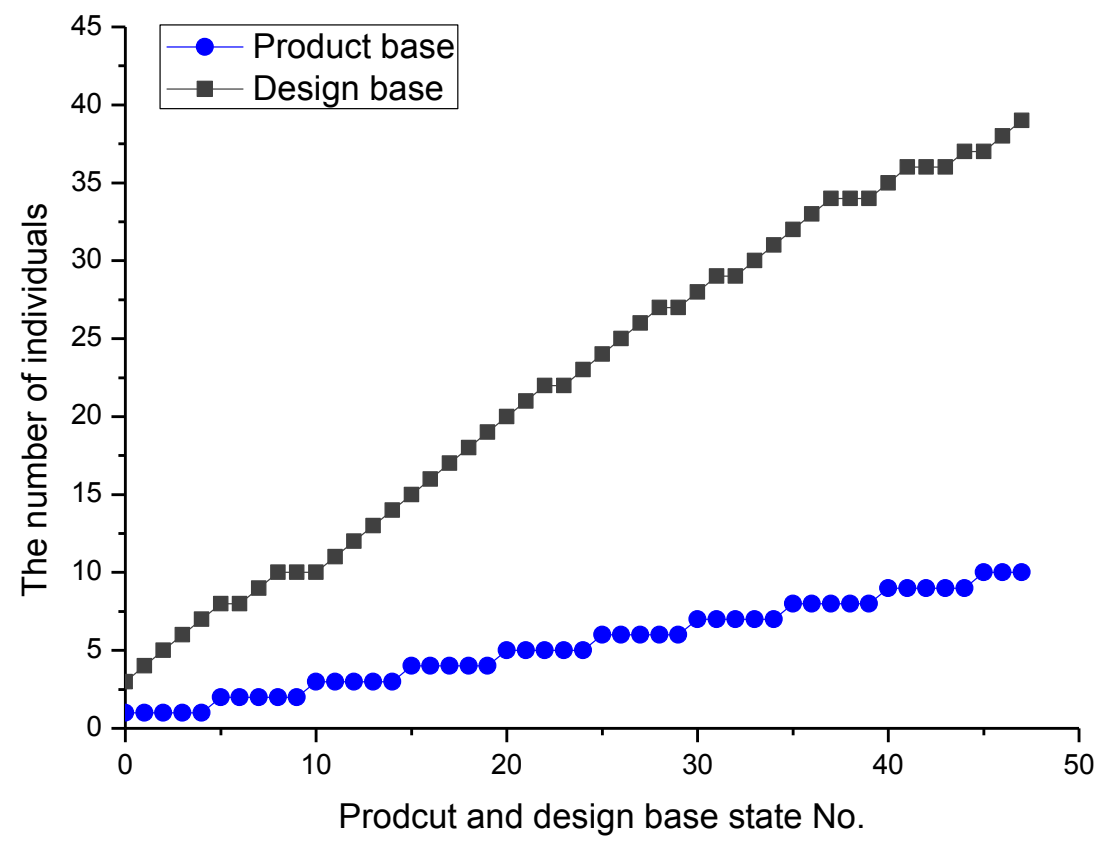

Fig. 6. Line chart of the number of individuals in product base and design base.

A histogram of the number of generations is shown in Fig. 7, from which a decreasing trend emerges. With user involvement, the product design process will stop if user finds or is satisfied with one product from product base. Otherwise, IGA-based product design starts. It is noted that the incensement of the number of individuals in product base and design base helped users reduce their operating process. It took a shorter time to meet users' demand, and obviously led to less fatigue. Ten or less generations in one IGA process is acceptable, and some users can even find the satisfying individuals before IGA design process with only two or three click operations. The generation frequency is 0 for them.

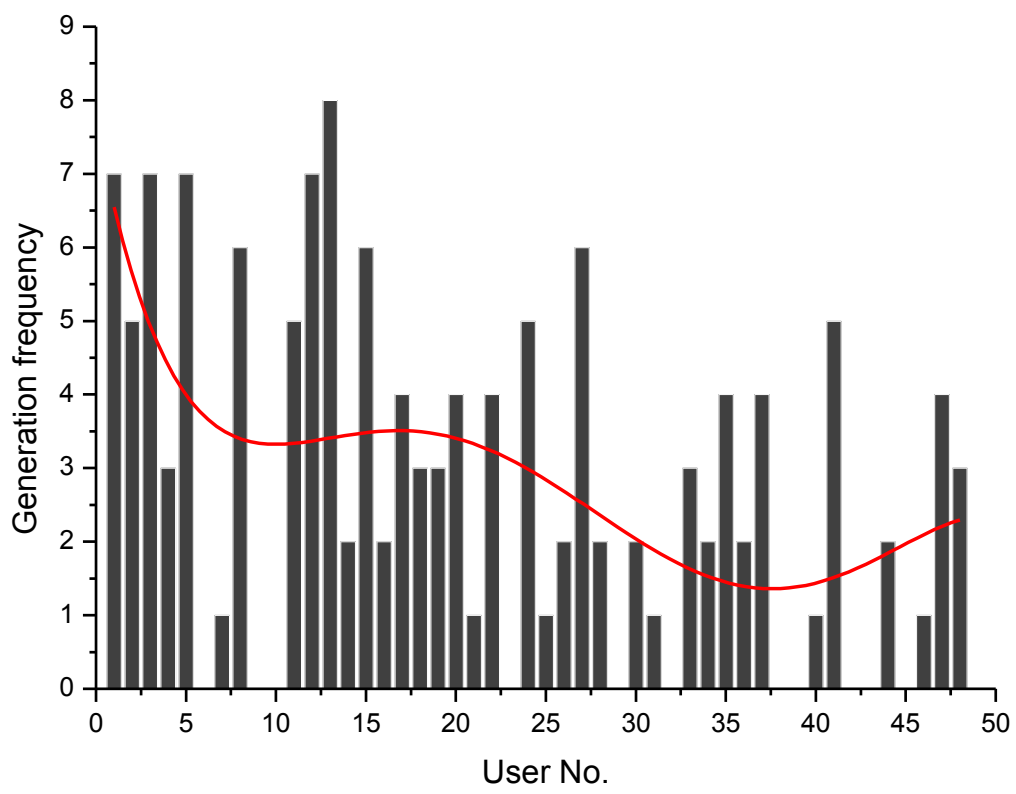


Fig. 7. Histogram of the number of generations undertaken by users.

An individual selected randomly from the current population will be replaced by the design scheme in design base that is the nearest to the current user preference at the probability $R(t)$ if there is individual in design base whose feature coincidence number is more than $\varepsilon$. A line chart of the ratio of preference case injection in one user's design process is shown in Fig. 8. It is regarded as 1 if the users find the most satisfying individual directly from product base. The increment of the number of individuals in design base leads to more frequent happening of preference case injection. Therefore the ratio has a growing trend.

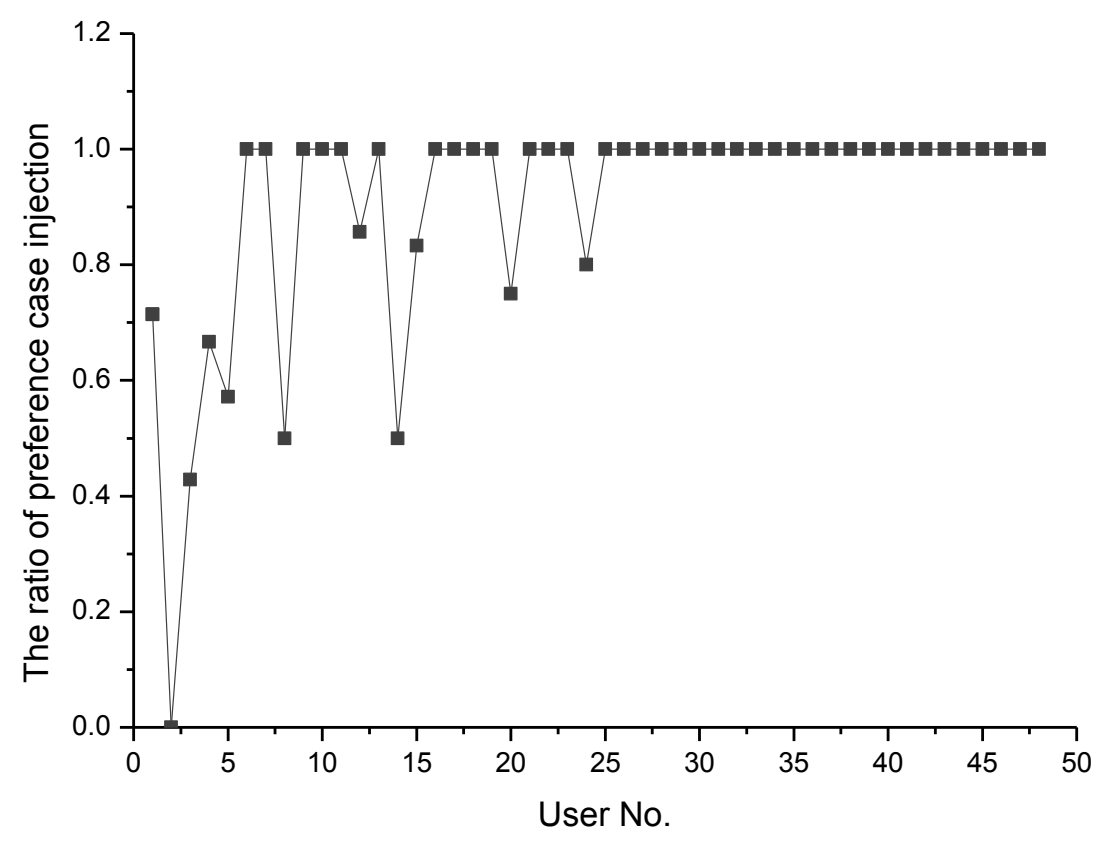

Fig. 8. Line chart of the ratio of preference case injection.

User responses to two questions are summarized in Fig. 9. Higher is better. For Q1, the mean is 3.39, and the median number is 3.50. For Q2, the mean is 4.06 , and the median number is 4.00 . Basically, users are satisfied with their final result and can accept the operating experience during design process. The experience can still be improved by beautifying system interface. 


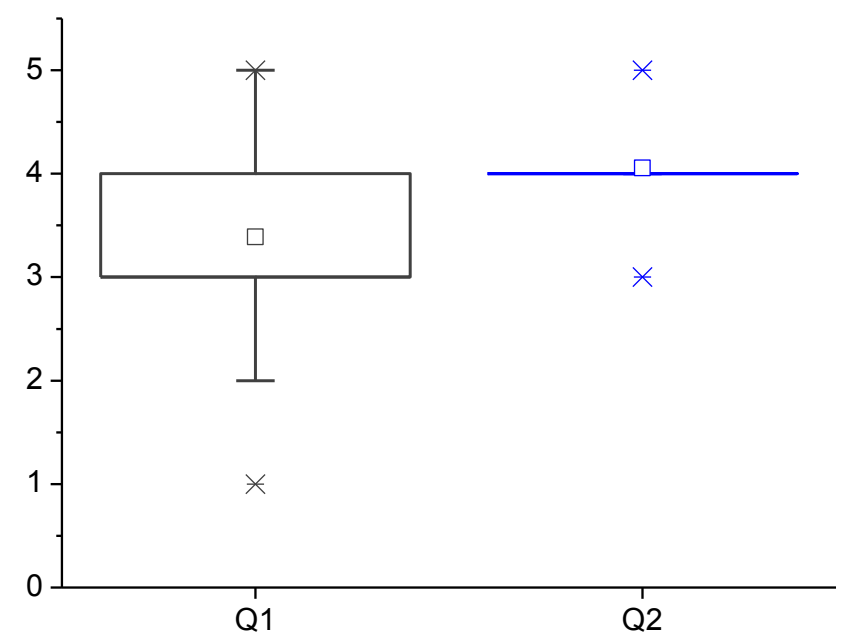

Fig. 9. Users' responses to two questions.

Now, two issues are focused on here. First, the initial states of product base and design base are discussed. In our experiment, they are set randomly, which represents only one situation, but other different initial settings do not affect the feasibility. For the initial states, the individuals in product base are less than those in design base. Even if the individual quantity of design base is set to be smaller in the initial stage, it will still exceed that of product base in middle stage because of its faster growth. In other words, the quantitative relationship between design base and product base of initial states don't affect the feasibility of the approach. Similarly, the changes in the numbers of individuals in initial design base and product base will also have no influence. No matter how much individuals are in the design base and product base, the initial situation can always be regarded as a middle state of design iteration.

Second, the preference border parameter $\varepsilon$ is discussed. A smaller $\varepsilon$ means a more permissive condition for preference judgment, which leads to a higher ratio of preference case injection. Obviously, the number of individuals in design base will also have influence on case injection. To prove the rationality of $\varepsilon$ we set, another experiment is carried out. Except $\varepsilon$ and $m$, the individual quantity of design base, the other system parameters are not reset. Individuals in design base are created randomly. The $\varepsilon$ of 1, 3, 5, 7 and 9, and the $m$ of 5, 15 and 25 are respectively set. For each parameter combination, the same user carried the IGA-based design process independently three times, and generation frequency and the ratio of preference case injection are counted. 

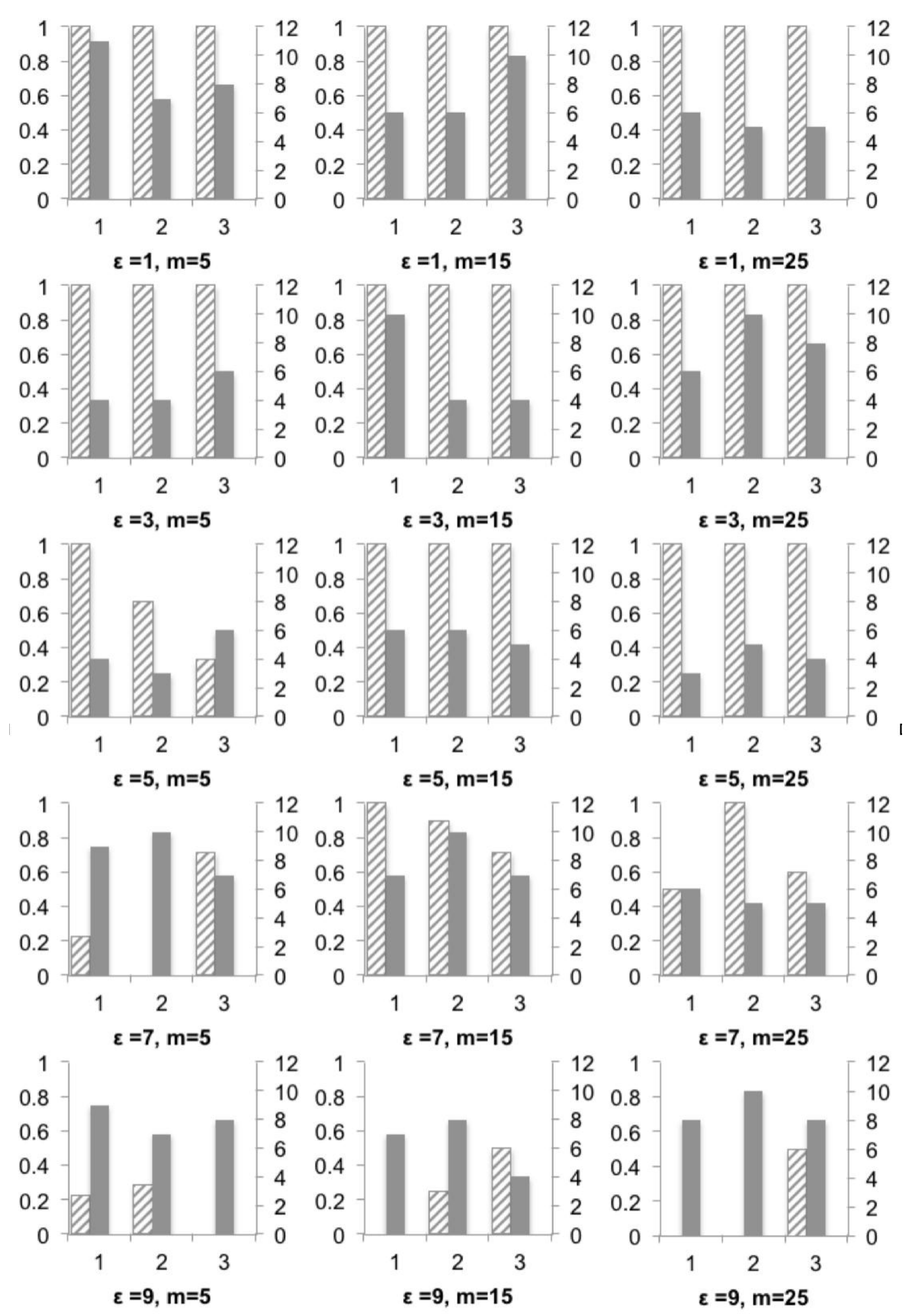

$\square$ The ratio of preference case injection

- Generation frequency 
Fig. 10. Experiment results with different $\varepsilon$ and $m$ combinations.

It can be seen from Fig. 10 that different $\varepsilon$ values have different influence on design efficiency reflected by generation frequency. When $m$ equals $5, \varepsilon=1$ corresponds to a high ratio of preference case injection but a high generation frequency, and larger $\varepsilon$ (e.g. $\varepsilon=7$ or 9) corresponds to a low ratio of preference case injection but also a high generation frequency, the design processes are relatively effective when $\varepsilon=3$ or 5 . The situation indicates that a smaller $\varepsilon$ leads to more often but less accurate case injections. On the contrary, a larger $\varepsilon$ leads to more accurate case injections, but design base knowledge can't be fully utilized. With the increase of $m$, there are more valuable individuals can be used to improve design efficiency. The trend is particularly visible when $\varepsilon=1$ or 7 . Although this trend isn't obviously reflected, $\varepsilon=5$ can stably sustain the design efficiency, which is the most acceptable compared with other $\varepsilon$ values.

The approach we propose is superior to other traditional approaches. For qualitative analysis, compared with traditional interactive modes in other methods such as slides and input boxes, 'single click' mode the approach adopts for user interaction has its advantages, which moderates operation complexity in design process and then accelerates customers to find their most satisfied individuals. The interactive mode lessens operational fatigue to the large extent because each generation evaluation only needs one click operation. For quantitative analysis, we achieve a traditional IGA-based design system having the same 'single click' interactive mode, and ask participants to design tablet PC again without changing other settings. The number of average generations and average time consumption for finding the most satisfying individuals are compared respectively in table 5 . Customers who can directly find the most satisfying individuals from product base are not taken into consideration in order to guarantee comparability.

Our approach, which integrates design iteration, obviously improves customers' customization efficiency. According to the comparison, even if we exclude those who can find the most satisfying individuals before actual IGA design process, the results show that our approach makes people spend less time, and experience less generation evaluation to obtain their satisfied design schemes compared with the traditional IGA.

\section{Table 5}

Comparison of the number of average generations and average time consumption

\begin{tabular}{ccc}
\hline Items & Traditional IGA & $\begin{array}{c}\text { The approach we } \\
\text { propose }\end{array}$ \\
\hline $\begin{array}{c}\text { The number of average } \\
\text { generations }\end{array}$ & 9 & 3.6 \\
Average time consumption & $162.94 \mathrm{~s}$ & $69.69 \mathrm{~s}$ \\
\hline
\end{tabular}

Based on the above discussion, in this research, the applicability of collaborative product design considering product-design evolutionary process is showen. There are clear indications to reflect the value of product and design scheme knowledge in customized design to improve design efficiency. Being satisfied with the result of the proposed approach, most of people consider the operating experience to be acceptable.

\section{Conclusion}

As the effective utilization of product information and design knowledge accumulated in 
design iteration could help manufacturers save costs and improve product design effectiveness, on the basis of IGA, an approach of collaborative product customization integrating design iteration is proposed in the paper, in which product design is regarded as the bidirectional evolution between products and design schemes, and the concept of product family is extended to that of design family, fully utilizing the value of existing products and generated designs. In the approach, a mechanism used to search the optimal individuals from product base is added before the product design based on IGA starts, and the identification process of customers' preference is integrated into the design process, thus the customers could effectively figure out their optimal individual. Meanwhile, the design scheme generated in the design process is added as individual into design base so as to improve the following itineration. In order to testify the efficiency of the proposed approach, as well as, to demonstrate its implementation in detail, the system developed from the approach is applied into table PC design, with completely considering customers fatigue by interaction of "single click". The experiment results verify that the approach is effective to meet customers' demand by making them quickly find out their satisfying individual, without causing too much fatigue.

Some limitation of the proposed approach exists. When the approach is used to customize new released products or those with relatively low upgraded rate, its efficiency can't be fully shown, because product base may have so limited individuals that it can't play its guiding role in following design process. Although individuals in product base can be gradually accumulated, for those products, time may become a bottleneck.

In this paper, the individual product with small size is organized and listed for choosing in product base, while in real production environment, product quantity is usually much larger, especially for the ordinary consumers' good design and artwork design. Therefore, it is necessary to make sure the proposed approach is still effective in real production environment with product quantity of hundreds in future. For this, our research will further explore a more effective way to organize and present product knowledge in order to better adapt to the real production situation. Besides, an innovative business model that contains not only the design chain but also value chain should be proposed in the future research. As the production process is sometimes influenced by other factors, such as technology, capital and reliability, besides product diversity, they could be focused on in the following research.

\section{References}

Alemanni, M., Destefanis, F., \& Vezzetti, E. (2010). Model-based definition design in the product lifecycle management scenario. The International Journal of Advanced Manufacturing Technology, 52(1-4), 1-14.

Aquino Shluzas, L. M., \& Leifer, L. J. (2014). The insight-value-perception (iVP) model for user-centered design. Technovation, 34(11), 649-662.

Babbar-Sebens, M., \& Minsker, B. S. (2012). Interactive Genetic Algorithm with Mixed Initiative Interaction for multi-criteria ground water monitoring design. Applied Soft Computing, 12(1), 182-195.

Bernhardt, D., Liu, Q., \& Serfes, K. (2007). Product customization. European Economic 
Review, 51(6), 1396-1422.

Bush, B. J., \& Sayama, H. (2011). Hyperinteractive Evolutionary Computation. IEEE Transactions on Evolutionary Computation, 15(3), 424-433.

Cavusoglu, H., Cavusoglu, H., \& Raghunathan, S. (2007). Selecting a Customization Strategy Under Competition: Mass Customization, Targeted Mass Customization, and Product Proliferation. IEEE Transactions on Engineering Management, 54(1), 12-28.

Chandrasegaran, S. K., Ramani, K., Sriram, R. D., Horváth, I., Bernard, A., Harik, R. F., \& Gao, W. (2013). The evolution, challenges, and future of knowledge representation in product design systems. Computer-Aided Design, 45(2), 204-228.

Cheung, W. M., Marsh, R., Griffin, P. W., Newnes, L. B., Mileham, A. R., \& Lanham, J. D. (2015). Towards cleaner production: a roadmap for predicting product end-of-life costs at early design concept. Journal of Cleaner Production, 87, 431-441.

Cho, S.-B. (2002). Towards Creative Evolutionary Systems with Interactive Genetic Algorithm. Applied Intelligence, 16(2), 129-138.

Chusilp, P., \& Jin, Y. (2005). Impact of Mental Iteration on Concept Generation. Journal of Mechanical Design, 128(1), 14-25.

Donnelly, K., Beckett-Furnell, Z., Traeger, S., Okrasinski, T., \& Holman, S. (2006). Eco-design implemented through a product-based environmental management system. Journal of Cleaner Production, 14(15-16), 1357-1367.

Dou, R., \& Zong, C. (2014). Application of Interactive Genetic Algorithm based on hesitancy degree in product configuration for customer requirement. International Journal of Computational Intelligence Systems, 7(sup2), 74-84.

Du, X., Jiao, J., \& Tseng, M. M. (2005). Understanding customer satisfaction in product customization. The International Journal of Advanced Manufacturing Technology, 31(3-4), 396-406.

Fung, C. K. Y., Kwong, C. K., Chan, K. Y., \& Jiang, H. (2014). A guided search genetic algorithm using mined rules for optimal affective product design. Engineering Optimization, 46(8), 1094-1108.

Fung, K. Y., Kwong, C. K., Siu, K. W. M., \& Yu, K. M. (2012). A multi-objective genetic algorithm approach to rule mining for affective product design. Expert Systems with Applications, 39(8), 7411-7419.

Gong, D., Yao, X., \& Yuan, J. (2009). Interactive Genetic Algorithms with Individual Fitness not Assigned by Human. Journal of Universal Computer Science, 15(13), 2446-2462.

Gong, D., Zhou, Y., \& Li, T. (2005). Cooperative Interactive Genetic Algorithm Based on User's Preference. International Journal of Information Technology, 11(10), 1-10.

Hastings, E. J., Guha, R. K., \& Stanley, K. O. (2009). Interactive Evolution of Particle Systems for Computer Graphics and Animation. IEEE Transactions on Evolutionary Computation, 13(2), 418-432.

Hinckeldeyn, J., Dekkers, R., Altfeld, N., \& Kreutzfeldt, J. (2014). Expanding bottleneck 
management from manufacturing to product design and engineering processes. Computers \& Industrial Engineering, 76, 415-428.

Hsiao, S.-W., Chiu, F.-Y., \& Lu, S.-H. (2010). Product-form design model based on genetic algorithms. International Journal of Industrial Ergonomics, 40(3), 237246.

Jin, H., \& Peng, W. (2009). Study on Product Design and Development Based on Design Knowledge Base (Vol. 1, pp. 463-466). Presented at the 2th International Symposium on Computational Intelligence and Design, Changsha, China: IEEE.

Jun, S., Jeon, Y.-H., Rho, J., \& Lee, D. (2006). Application of Collaborative Optimization Using Genetic Algorithm and Response Surface Method to an Aircraft Wing Design. Journal of Mechanical Science and Technology, 20(1), 133-146.

Kaljun, J. (2014). Intelligent support for defining aesthetical, ergonomical and materialproperties of designed product. Tehnički Vjesnik, 21(4), 835-842.

Kim, H.-S., \& Cho, S.-B. (2000). Application of interactive genetic algorithm to fashion design. Engineering Applications of Artificial Intelligence, 13(6), 635-644.

Kimura, F., Matoba, Y., \& Mitsui, K. (2007). Designing Product Reliability based on Total Product Lifecycle Modelling. CIRP Annals - Manufacturing Technology, 56(1), 163-166.

Kuzma, M., Jaksa, R., \& Sincak, P. (2009). Clustering of Users Inputs in Multi-User Interactive Evolutionary Font Design (pp. 41-46). Presented at the 5th International Symposium on Applied Computational Intelligence and Informatics, imişoara, Romania: IEEE.

Lee, J. H., \& Chang, M. L. (2010). Stimulating designers' creativity based on a creative evolutionary system and collective intelligence in product design. International Journal of Industrial Ergonomics, 40(3), 295-305.

Li, S., Nahar, K., \& Fung, B. C. M. (2013). Product customization of tablet computers based on the information of online reviews by customers. Journal of Intelligent Manufacturing, 26(1), 97-110.

Liu, Y., Zhang, Z., \& Liu, Z. (2011). Customized configuration for hierarchical products: component clustering and optimization with PSO. The International Journal of Advanced Manufacturing Technology, 57(9-12), 1223-1233.

Li, W. D., Lu, W. F., Fuh, J. Y. H., \& Wong, Y. S. (2005). Collaborative computer-aided design-research and development status. Computer-Aided Design, 37(9), 931-940.

Llinares, C., \& Page, A. F. (2011). Kano's model in Kansei Engineering to evaluate subjective real estate consumer preferences. International Journal of Industrial Ergonomics, 41(3), 233-246.

Lorenzini, G., Biserni, C., Estrada, E. D., Isoldi, L. A., dos Santos, E. D., \& Rocha, L. A. O. (2014). Constructal Design of Convective Y-Shaped Cavities by Means of Genetic Algorithm. Journal of Heat Transfer, 136(7), 071702-071702.

Luh, P. B., Liu, F., \& Moser, B. (1999). Scheduling of design projects with uncertain number of iterations. European Journal of Operational Research, 113(3), 575592. 
Marion, T. J., Meyer, M. H., \& Barczak, G. (2015). The Influence of Digital Design and IT on Modular Product Architecture: Modular Product Architecture. Journal of Product Innovation Management, 32(1), 98-110.

Mazhoud, I., Hadj-Hamou, K., Bigeon, J., \& Remy, G. (2012). Interval-based global optimization in engineering using model reformulation and constraint propagation. Engineering Applications of Artificial Intelligence, 25(2), 404417.

Mok, P. Y., Wang, X. X., Xu, J., \& Kwok, Y. L. (2012). Fashion sketch design by interactive genetic algorithms. AIP Conference Proceedings, 1499, 357-364.

Mok, P. Y., Xu, J., Wang, X. X., Fan, J. T., Kwok, Y. L., \& Xin, J. H. (2013). An IGA-based design support system for realistic and practical fashion designs. Computer-Aided Design, 45(11), 1442-1458.

Nathan-Roberts, D., \& Liu, Y. (2015). Testing aesthetic and function design preference for touch screen and non-touch screen mobile phones using interactive genetic algorithms. International Journal of Human-Computer Interaction, 31(4), 253-262.

Park, J., Han, S. H., Kim, H. K., Oh, S., \& Moon, H. (2013). Modeling user experience: A case study on a mobile device. International Journal of Industrial Ergonomics, 43(2), 187-196.

Peng, D. X., Heim, G. R., \& Mallick, D. N. (2014). Collaborative Product Development: The Effect of Project Complexity on the Use of Information Technology Tools and New Product Development Practices. Production and Operations Management, 23(8), 1421-1438.

Petiot, J.-F., \& Dagher, A. (2010). Preference-oriented form design: application to cars' headlights. International Journal on Interactive Design and Manufacturing (IJIDeM), 5(1), 17-27.

Poirson, E., Dépincé, P., \& Petiot, J.-F. (2007). User-centered design by genetic algorithms: Application to brass musical instrument optimization. Engineering Applications of Artificial Intelligence, 20(4), 511-518.

Quiroz, J. C., Louis, S. J., Banerjee, A., \& Dascalu, S. M. (2009). Towards creative design using collaborative interactive genetic algorithms. In Evolutionary Computation, 2009. CEC'09. IEEE Congress on (pp. 1849-1856). IEEE.

Renner, G., \& Ekárt, A. (2003). Genetic algorithms in computer aided design. Computer-Aided Design, 35(8), 709-726.

Risdiyono, \& Koomsap, P. (2013). Design by customer: concept and applications. Journal of Intelligent Manufacturing, 24(2), 295-311.

Rodriguez, L., Diago, L., \& Hagiwara, I. (2011). Interactive Genetic Algorithm with fitness modeling for the development of a color simulation system based on customer's preference. Japan Journal of Industrial and Applied Mathematics, 28(1), 27-42.

Smith, R. P., \& Tjandra, P. (1998). Experimental observation of iteration in engineering design. Research in Engineering Design, 10(2), 107-117.

Smith, S., Smith, G. C., Jiao, R., \& Chu, C.-H. (2012). Mass customization in the product life cycle. Journal of Intelligent Manufacturing, 24(5), 877-885. 
Takagi, H. (2001). Interactive evolutionary computation: fusion of the capabilities of EC optimization and human evaluation. Proceedings of the IEEE, 89(9), 12751296.

Thirumalai, S., \& Sinha, K. K. (2011). Customization of the online purchase process in electronic retailing and customer satisfaction: An online field study. Journal of Operations Management, 29(5), 477-487.

Verstegen, D. M. L., Barnard, Y. F., \& Pilot, A. (2006). Which events can cause iteration in instructional design? An empirical study of the design process. Instructional Science, 34(6), 481-517.

Wells, J. D., Valacich, J. S., \& Hess, T. J. (2011). What Signals Are You Sending? How Website Quality Influences Perceptions of Product Quality and Purchase Intentions. MIS Quarterly, 35(2), 373-396.

Wu, Z. Y., Ming, X. G., Wang, Y. L., \& Wang, L. (2014). Technology solutions for product lifecycle knowledge management: framework and a case study. International Journal of Production Research, 52(21), 6314-6334.

$\mathrm{Xu}$, Y., Bernard, A., Perry, N., Xu, J., \& Sugimoto, S. (2014). Knowledge evaluation in product lifecycle design and support. Knowledge-Based Systems, 70, 256267.

Yang, Y., Zhang, X., Liu, F., \& Xie, Q. (2005). An internet-based product customization system for CIM. Robotics and Computer-Integrated Manufacturing, 21(2), 109-118.

Yannou, B., Cluzel, F., \& Dihlmann, M. (2013). Evolutionary and interactive sketching tool for innovative car shape design. Mechanics \& Industry, 14(01), 1-22.

Zheng, C., Bricogne, M., Le Duigou, J., \& Eynard, B. (2014). Survey on mechatronic engineering: A focus on design methods and product models. Advanced Engineering Informatics, 28(3), 241-257. 


\section{Graphical abstract}

The existing products and the increasing design schemes can be fully organized as valuable knowledge to iteratively improve later design process through the design iteration-based approach using IGA. A system prototype is developed based the approach with a GUI whose' single click' interactive mode without slides or input boxes relieves user fatigue. With the help of the system, a case study for tablet PC design is given, which verified the effectiveness.

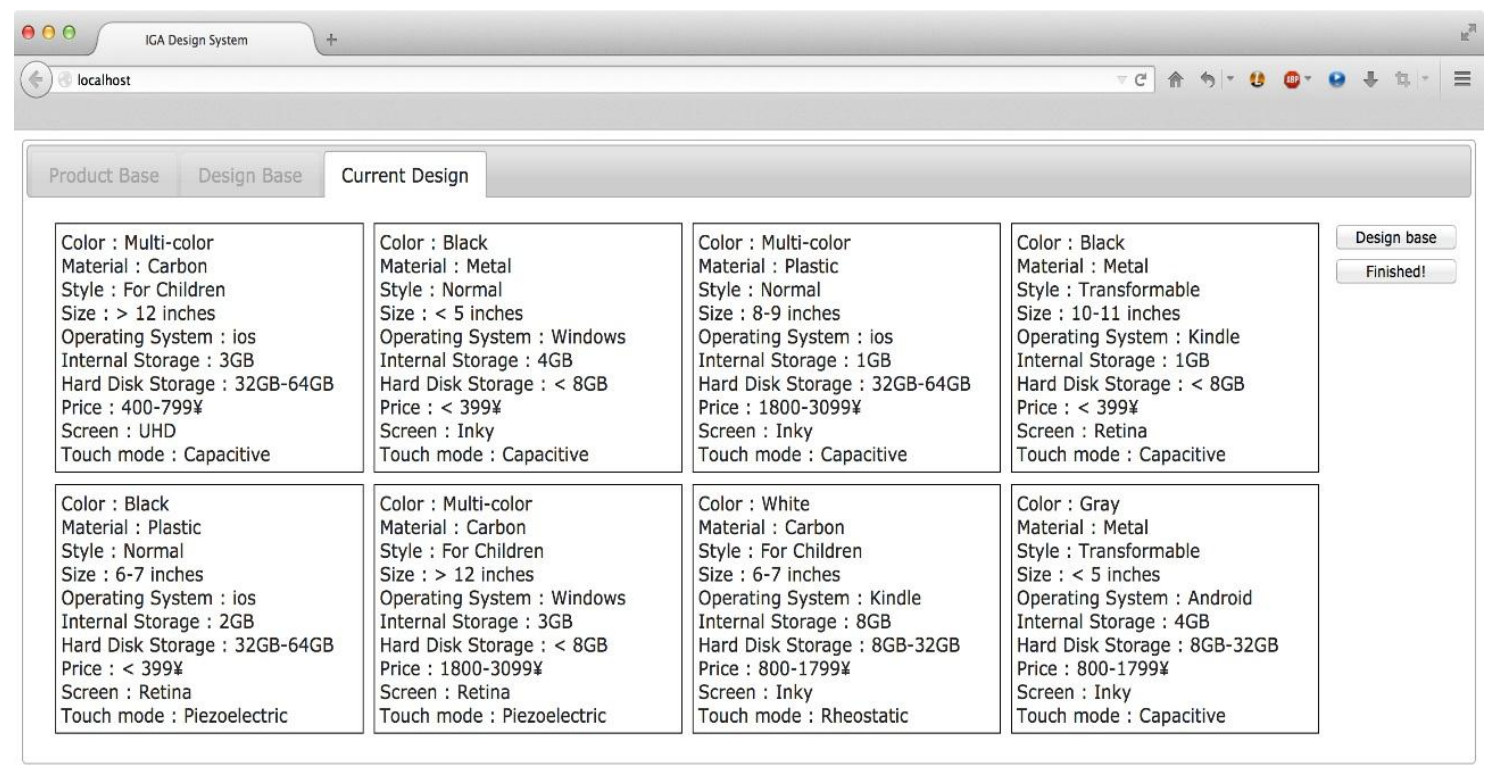

